\title{
LETTER
}

\section{The Triple-Negative Breast Cancer Database: an omics platform for reference, integration and analysis of triple-negative breast cancer data}

\author{
Rajesh Raju ${ }^{\dagger}$, Aswathy Mary Paul ${ }^{\dagger}$, Vivekanand Asokachandran, Bijesh George, Lekshmi Radhamony, \\ Meena Vinaykumar, Reshmi Girijadevi ${ }^{*}$ and Madhavan Radhakrishna Pillai
}

Clustering the transcriptomic profile of 587 triple-negative breast cancer (TNBC) cases extracted from 21 breast cancer microarray datasets relying on the lack of transcriptlevel expression of estrogen receptor (ER), progesterone receptor (PR) and human epidermal growth factor receptor 2 (Her2), Lehmann and colleagues have categorized the TNBCs into seven subgroups [1]. From more than 1,000 clinical samples that were characterized as TNBCs by immunohistochemistry, we report the first compendium of molecular expression-level alterations as a value-added resource for extended research. This open-access manually curated resource, the Triple Negative Breast Cancer Database (TNBCDb) [2], currently hosts 144 microRNA, 2,696 mRNA, 106 protein and 13 post-translational modification alterations in TNBC tissues.

The TNBC tissues are categorized into lymph nodepositive, lymph node-negative and lymph node metastatic tissues, or otherwise as TNBC-not specified. TNBCDb hosts experimentally reported alterations in these tissues compared with $\mathrm{ER}^{+}, \mathrm{ER}^{+} \mathrm{PR}^{+}, \mathrm{Her}^{+}, \mathrm{ER}^{+} \mathrm{PR}$ ${ }^{+} \mathrm{Her} 2^{-}, \mathrm{ER}^{-} \mathrm{PR}^{-} \mathrm{Her} 2^{+}$, luminal $\mathrm{A}$, luminal $\mathrm{B}$ and nonTNBC (if not specified) or matched adjacent normal, unmatched normal breast or parenchyma tissues as analyzed. The ethnicity/origin as provided by the authors/deduced, the frequency of observation of the molecular alterations in terms of the number of patient samples analyzed per study, fold values of expression, experiment platform used and the reference to corresponding research articles are provided for the curated records.

TNBCDb also hosts the comparative molecular profile of 39 TNBC cell lines compared among themselves as well as with 55 non-TNBC cell lines as a tool for selection of appropriate cell lines for specific studies on the basis of their molecular background. Effective visualization of genes differentially regulated in TNBC tissues and cell lines and, further, the signaling pathways $[3,4]$, biological processes, molecular functions, cellular localization [5], protein-protein interactions [6], microRNA targets and RNA-level co-expressed genes [7] that are associated with each type of molecule, is enhanced through unique features designated the 'TNBCDb viewer' and the 'Network viewer' (Figure 1).

Considering the heterogeneity of breast cancers, we believe the TNBCDb will serve as a platform for selection of therapeutically relevant molecular entities from the tissue and cell line information and also for the selection of appropriate cell lines for evaluation of therapeutic targets in the direction of personalized therapy. We request suggestions from the scientific community to improve and keep this resource up to date with more information/clinical parameters through an online portal [9]. We believe that this initiative will help us to maintain $\mathrm{TNBCDb}$ as a global reference, integration and analysis platform for TNBC.

* Correspondence: reshmi@rgcb.res.in

${ }^{\dagger}$ Equal contributors

Computational Biology Group, Cancer Research Program-9, Rajiv Gandhi Centre for Biotechnology, Poojappura, Thiruvananthapuram 695014, Kerala, India 


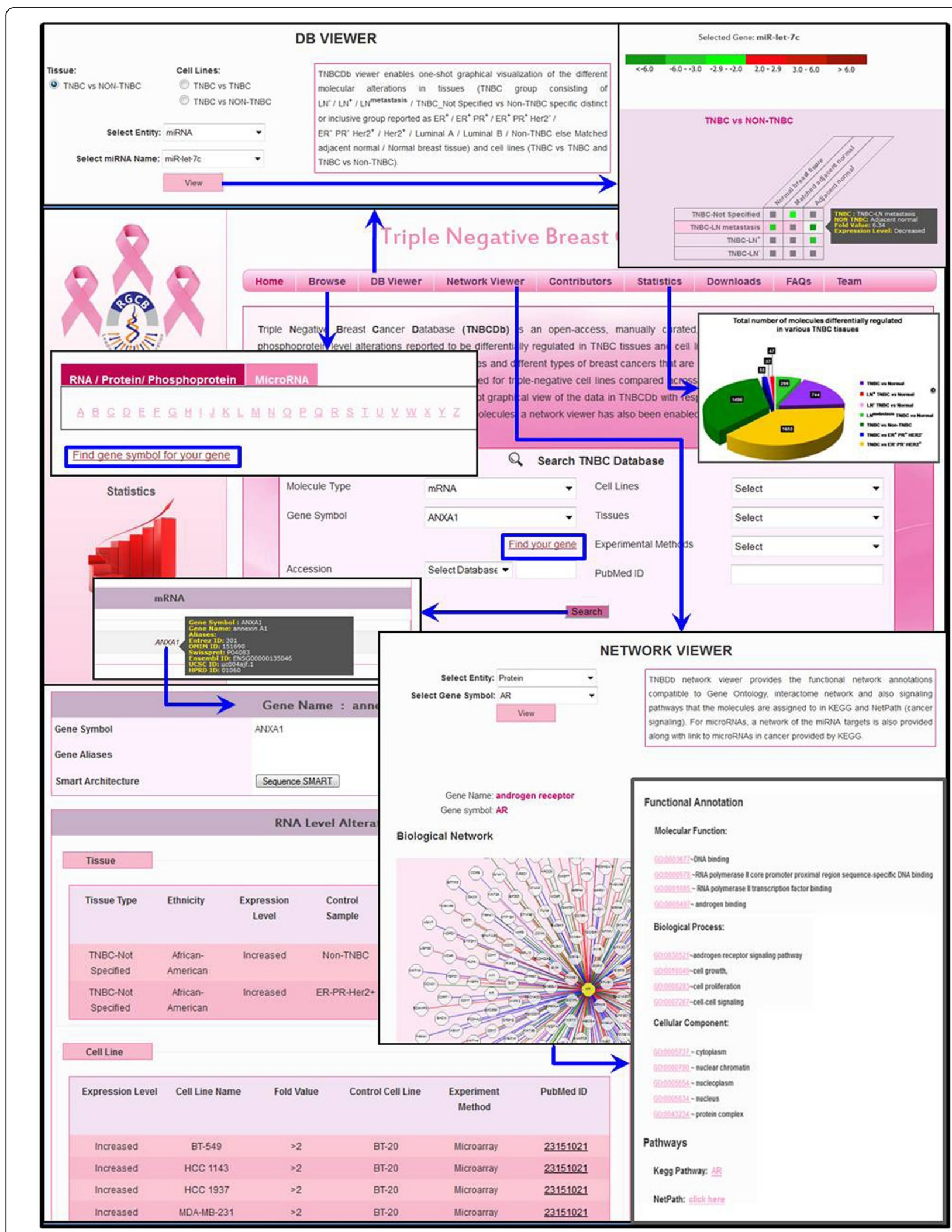

Figure 1 (See legend on next page.) 
(See figure on previous page.)

Figure 1 Navigation through the Triple-Negative Breast Cancer Database. The Triple Negative Breast Cancer Database (TNBCDb) has features enabled to search molecule types by molecule gene symbol and different accession numbers (Entrez Gene, OMIM, SwissProt and MiRbase IDs). To help researchers search genes by gene symbol, a 'find your gene' feature has been incorporated that allows selection of molecules from the browse page or helps find the corresponding gene symbols for your molecule. For each of the microRNAs, mRNAs, proteins or phosphoproteins, their differential regulation in tissues as well as the cell lines is provided as available. The TNBCDb viewer has been enabled to facilitate visualization of the regulation of molecules in triple-negative breast cancer (TNBC) tissue(s) versus different types of non-TNBC tissues and for molecules in one TNBC cell line with another TNBC cell line and with different non-TNBC cell lines highlighting their fold-change values. The network viewer enables the integrated view of the interactions, co-expressions, biological processes, molecular function, cellular compartments and the biological pathways that are reported to be associated with each of the molecules in TNBCDb. Further, researchers can also search by tissue type, cell line name, experiment method and PubMed IDs as individual or multiple queries. The TNBCDb data in the complete form are available for free download [8]. ER, estrogen receptor; Her2, human epidermal growth factor receptor 2; LN, lymph node; PR, progesterone receptor.

\section{Abbreviations}

ER: Estrogen receptor; Her2: Human epidermal growth factor receptor 2; PR: Progesterone receptor; TNBC: Triple-negative breast cancer; TNBCDb: Triple Negative Breast Cancer Database.

\section{Competing interests}

The authors declare that they have no competing interests.

\section{Authors' contributions}

$R G, M R P$ and RR conceived and designed the study. RR, AMP and VA screened the articles and documented the information. AMP, VA, BG, LR and MV were involved in the development of the website. All authors read and approved the final manuscript

\section{Acknowledgements}

The authors acknowledge the support and suggestions from Professor Beela Sarah Mathew of the Regional Cancer Centre, Thiruvananthapuram, India and from Dr TR Santosh Kumar and Dr KB Harikumar of the Rajiv Gandhi Centre for Biotechnology, Poojappura, Thiruvananthapuram, India. GR is supported by the Indian Council of Medical Research's Viral Disease Network Program (VIR/8/2011-ECD-1 to RGD), and AMP, AV and BG are supported by grants from Department of Biotechnology, India (BT/PR14209/BID/07/328/2010 and BT/PR5890/BID/7/407/2012). The authors thank all contributors of data.

\section{Published online: 04 December 2014}

\section{References}

1. Lehmann BD, Bauer JA, Chen X, Sanders ME, Chakravarthy AB, Shyr $Y$, Pietenpol JA: Identification of human triple-negative breast cancer subtypes and preclinical models for selection of targeted therapies. J Clin Invest 2011, 121:2750-2767.

2. Triple-Negative Breast Cancer Database. [www.tnbcdb-rgcb-res.in, www.rgcb.res.in/tnbcdb]

3. Raju R, Nanjappa V, Balakrishnan L, Radhakrishnan A, Thomas JK, Sharma J, Tian M, Palapetta SM, Subbannayya T, Sekhar NR, Muthusamy B, Goel R, Subbannayya Y, Telikicherla D, Bhattacharjee M, Pinto SM, Syed N, Srikanth MS, Sathe GJ, Ahmad S, Chavan SN, Kumar GS, Marimuthu A, Prasad TS, Harsha HC, Rahiman BA, Ohara O, Bader GD, Sujatha Mohan S, Schiemann WP, Pandey A: NetSlim: high-confidence curated signaling maps. Database 2011, 2011: bar032.

4. Ogata H, Goto S, Sato K, Fujibuchi W, Bono H, Kanehisa M: KEGG: Kyoto Encyclopedia of Genes and Genomes. Nucleic Acids Res 1999, 27:29-34.

5. Carbon S, Ireland A, Mungall CJ, Shu S, Marshall B, Lewis S, AmiGO Hub; Web Presence Working Group: AmiGO: online access to ontology and annotation data. Bioinformatics 2009, 25:288-289.

6. Keshava Prasad TS, Goel R, Kandasamy K, Keerthikumar S, Kumar S, Mathivanan S, Telikicherla D, Raju R, Shafreen B, Venugopal A, Balakrishnan L, Marimuthu A, Banerjee S, Somanathan DS, Sebastian A, Rani S, Ray S, Harrys Kishore CJ, Kanth S, Ahmed M, Kashyap MK, Mohmood R, Ramachandra YL, Krishna V, Rahiman BA, Mohan S, Ranganathan P, Ramabadran S, Chaerkady R, Pandey A: Human Protein Reference Database - 2009 update. Nucleic Acids Res 2009, 37:D767-D772.
7. Giles CB, Girija-Devi R, Dozmorov MG, Wren JD: mirCoX: a database of miRNA-mRNA expression correlations derived from RNA-seq meta-analysis. BMC Bioinformatics 2013, 14:S17.

8. Triple-Negative Breast Cancer Database. [www.tnbcdb-rgcb-res.in/download. php, www.rgcb.res.in/tnbcdb/download.php]

9. Triple-Negative Breast Cancer Database FAQ. [www.tnbcdb-rgcb-res.in/ faq.php]

\section{doi:10.1186/s13058-014-0490-y}

Cite this article as: Raju et al:: The Triple-Negative Breast Cancer

Database: an omics platform for reference, integration and analysis of triple-negative breast cancer data. Breast Cancer Research 2014 16:490. 